\title{
Returning from study abroad and transitioning as a scholar: Stories of foreign PhD holders from Kazakhstan.
}

\author{
Kuzhabekova, A., Sparks, J., \& Temerbayeva, A. \\ Research in Comparative and International Education (2019), 14(3), 412-430.
}

\section{Word count: 9, 671}

\begin{abstract}
The article reports the results of an interview-based study exploring how international Ph.D. holders re-integrate into research environment in Kazakhstan. One of the main results consistent with prior studies is that returning scholars face a poor access to international and domestic scholarly societies. Interaction with external peers is problematic due to insufficient funding available for conference participation. Lack of communication with domestic scholarly community is related to its inaccessibility for junior researchers, as well as to its propensity to operate as an informal network of senior scholars controlling protectionist distribution of funding and exerting influence on administrative and policy decision-making in academia. To counteract the informal networks returning scholars get organized into alterative informal networks aimed at information exchange, mutual support and lobbying of interests. This transformative activity of junior scholars cannot be explained with the dominant structural theories in the existing research. An alternative Agency Theory interpretation is considered.
\end{abstract}

\section{Keywords}

research capacity, returning scholars, readjustment, study abroad

\section{Introduction}

Increasing national research capacity as an essential precondition for innovation-driven economic growth has become one of the top items on the reform agenda of many transitional economies (World Bank, 2010). Internationalization of higher education is often viewed as an important mechanism for modernization and stimulating competitiveness of higher education in terms of the ability to contribute with research and innovation (Knight and DeWitt, 1997). Study abroad in particular, is considered an effective solution, which allows to ensure the supply of high-quality human resources to countries, where there is a deficit of such resources and the domestic higher educational system is not yet on par with universities abroad in the quality of research training provided (Gribble, 2008). While some researchers question the befits of sending students abroad for countries of the global South due to the inevitable loss of the most qualified research cadre as a result of brain drain (Kapur and McHale, 2005), sending and receiving universities, national governments, and international organizations provide a variety of scholarships to students, who choose to pursue their higher education abroad (Perna, et al., 2014; Bhandari, 2007). The number of international students across the world, including doctoral students, has been consistently increasing since 2001 (Choudaha, 2017). 
Many studies within the field of international higher education try to gain better understanding about drivers of internationalization, national and international trends, national and institutional approaches, individual student or faculty experiences, as well as short-term and long-term outcomes at the individual, organizational, and national levels (Kehm and Teichler, 2007; Nicolescu and Galalae, 2013; Yudkevich et al., 2016). However, based on the review of the existing literature, more studies need to be conducted to better understand how the participants of study abroad programs transition to the environment of their home countries. Moreover, there is an evident lack of studies on the experiences of post-graduate students in general, and on the transition process of such students in non-Western countries more specifically. Finally, little is known about how returnees with doctoral degrees transition as scholars.

The purpose of the study is to achieve a greater understanding about the process of transition of doctoral returnees to their domestic research environments. We analyzed the case of such returnees in Kazakhstan, a transitional economy in post-Soviet Eurasia, which makes substantial investments in training its young researchers abroad in hope that this will lead to accelerated development of the national research and innovation system (Sagintayeva and Kurakbayev, 2013). The study will allow to fill the niche in the existing body of research on internationalization and will also inform policy makers in Eurasian and other transitional contexts as they develop policies aimed at supporting its internationally educated compatriots in the process of transition. The results of the study may help the governments to achieve the intended benefits of doctoral-level study abroad scholarships by increasing the effectiveness of post-study support systems.

\section{Contextual background}

Driven by the desire to stimulate economic growth via industrial diversification and innovation the government of Kazakhstan has been putting much effort in increasing the country's research capacity. Key government initiatives in this respect focus on (1) the creation of the modern research and innovation infrastructure, as well as (2) training and development of the national research cadre (State Program for the Development of Education and Science 2016-2020; State Program for Industrial and Innovation Development of Kazakhstan 2015-2019).

With respect to the second area of focus, the main mechanisms entail the reform of postgraduate education and promoting international mobility schemes supporting post-graduate training, research visits, and professional development of researchers abroad (Sagintayeva and Kurakbayev, 2013). Designed and administered under the influence of the Bologna Declaration signed by Kazakhstan in 2010, the international mobility schemes are expected to have a positive effect on the development of research capacity of Kazakhstani scholars, while the scholars themselves are expected to be able to become highly productive and internationally competitive researchers upon their return to Kazakhstan (Perna et al., 2015).

The most notable example of the mobility schemes is the Presidential "Bolashak" scholarship funding degree-leading education abroad. During 2005-2013, 213 students received "Bolashak" 
scholarships to pursue doctoral degrees in universities abroad (Perna et al., 2015). While specific statistics on other doctoral students is not available, the numbers should be increasing given that 66,623 Kazakhstani students were enrolled in higher education abroad in 2015, an increase of nearly $140 \%$ over the 28,249 who went abroad in 2006 (UNESCO Institute of Statistics, 2018). Many students were funded by their sending institutions in Kazakhstan, by the host universities abroad, by various international agencies (DAAD, Fullbright, International Monetary Fund, Asian Development Bank, Soros and Aga Khan Foundations and others), as well as by their own parents.

These educated young people have been coming back to Kazakhstan in increasing quantities and have been trying to integrate in the domestic research environment. No research has been conducted so far, to our knowledge, on how these individuals transition in Kazakhstani as researchers. Meanwhile, extensive literature on international mobility suggests that the positive effects of international mobility might be moderated by the transitional experiences of a returnee. Several bodies of literature, particularly relevant in this respect, are summarized in the subsequent section.

\section{Literature review}

In search for theoretical frames to analyze the experiences of returning Ph.D. scholars, we looked not only at the closely related literature on readjustment of students after study abroad, but also on literature from other fields of research dealing with different types of international mobility, which explored the process of re-integration upon return from an international stay. As a result, we identified five bodies of literature as suggesting useful insights for our study. These classes of literature are summarized below.

First, within international human resource management (HRM) literature, research on repatriation (return from international corporate assignment) and re-adjustment has been conducted since 1970s (Black et al., 1991). The main finding from the body of literature is that repatriation can present more difficulties than initial adjustment in international settings (Adler, 1981), that repatriation is often associated with unmet expectations (about career effects, professional experiences, salary, and personal and professional relations within and outside the employing organization), feeling of being undervalued, concerns about future career, and the resultant high turnover (Kraimer et al., 2012; Lazarova and Caligiuri, 2002; Suutari and Brewster, 2003).

One theoretical model in the HRM field, Black et al.' (1991) Model of International Adjustment, is particularly relevant for the analysis of re-adjustment of returning researchers. The model draws on an earlier hypothesis that the extent of re-adjustment depends on the returnee's expectations and their realization that their homeplace has not remained unchanged (Gullahorn and Gullahorn, 1963). Black et al.'s (1991) model identified a set of individual, job, organizational, and non-work variables that affect anticipatory repatriation adjustment (expectations) and in-country adjustment, as well as showed how the former can affect the latter and how adjustment and organization commitment can 
determine satisfaction and turnover (Figure 1). In addition, later studies, showed the link between the extent of re-adjustment and the availability of organizational support (Lazarova and Caligiuri, 2002) and job mentorship (Carraher et al., 2008).

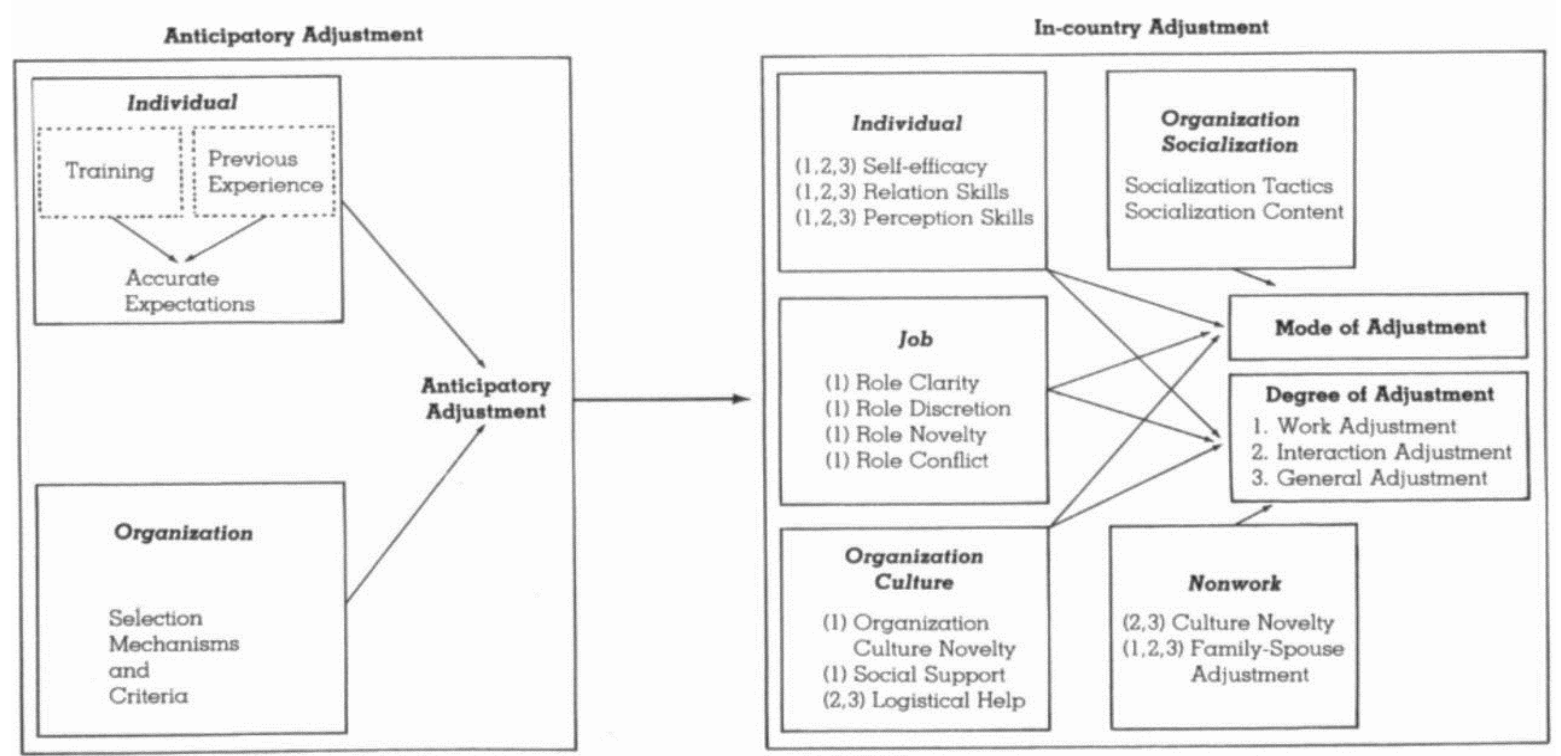

Figure 1. Model of International Adjustment Black et al.'(1991).

A more intricate picture of organizational socialization, identified as one of the factors in Black et al.'s (1991) model, is provided by the second body of literature within organizational management research. One of the topics of study in the field is organizational socialization of newly-hired employees. While returning scholars are not always newly hired (as in the case of those researchers who worked for a home university prior to their study abroad), assuming that organizations change, and a returnee never comes back to exactly the same organization, one may view re-adjustment as a form of organizational (re)socialization. Organizational socialization is understood as the process of learning aimed at reduction of uncertainty (Chao et al., 1994) through which newcomers move from being outsiders to becoming effective insiders (Wanberg, 2012) by learning the roles and routines related to one's job, work group, and organization.

A useful theory in this body of literature is Belongingness Theory, introduced by Baumeister and Leary (1995), which posits that good relationships and being incorporated with social networks are critically important during organizational socialization (Morrison, 2002). Newcomers not only learn new task and policies, but also start working with their colleagues more frequently and try to become integrated into the social fabric of their new organization (Bauer \& Erdogan, 2012). Re-adjustment, therefore, as a form of organizational socialization, is largely dependent on the relationships with colleagues.

The third relevant body of literature is research on academic sojourners in the field of international higher education. This literature explores academic sojourners - students and faculty returning from international stays in higher educational institutions. Much of the literature in the sphere describes the 
experiences of academic sojourners upon arrival to the host country and upon their return to their home country. Most notable metaphoric representations in the field include "culture shock" (anxiety experienced after exposure to a new culture), "reverse culture shock" (anxiety experienced upon return to one's home culture after a stay abroad) (Hall, 1959); and "cultural adjustment", i.e. getting used to a new set of cultural beliefs, values and norms or overcoming the culture shock (Biddle, 1979).

A theoretical distinction found in this literature and useful for the study of returning scholars is between different outcomes of cultural adjustment. Similar classifications of outcomes were suggested by Berry (1994) and Ward (2001), who distinguished between remaining mono-cultural (sticking exclusively to one's original or the newly learnt culture), becoming bi/multicultural (i.e. able to successfully operate in either of the cultures), and getting marginalized (i.e. remaining unassociated with either of the cultures). An alternative classification of adjustment outcomes was developed by Cox (2004). In his Cultural Identity Model four types of identity were stipulated: home-favored, host-favored, integrated and disintegrated.

The fourth body of literature comes from the field of research on highly skilled migrants (HSM), which in the past focused exclusively on "brain-drain"/"brain circulation" effects and reasons, but now explores academic migration issues in a more general sense. Migration of a scholar can be viewed as an extreme outcome of non-adjustment, which involves both departure from the employing organization and from the country. Exploring the reasons for move from one country to another by researchers may offer insights about factors associated with poor re-adjustment. A useful framework for analyzing migration decision of highly-skilled migrants (scientists) was suggested by Ackers (2005), who argued that one must combine the resource framework and the agency framework in the study of HSM. While the first framework allows one to analyze resources- and structure-related constraints, which a researcher may perceive as interfering with their research capacity, the agency framework allows to take into consideration individualistic and relational factors (relationships and networks).

Whilst the resource framework posits that prospects for economic improvement in terms of earnings is the most important factor for relocation of researchers in developing countries, the agency framework insists that researchers are mostly "knowledge migrants" vs. "economic" migrants" (Department of Trade and Industry, 2002, p.12) and are motivated not so much by better living conditions, as by better research conditions. Researchers expect a high quality of research facilities, access to research funding, recognition and a high status as a researcher in the society, independence and autonomy, as well as opportunities to work in research teams (Martin-Rovert, 2003, p. 1). Ackers (2001) added to this list of organizational factors meritocratic promotion and excellence promoting practices, and Hellemans (2001) emphasized the discouraging effect of cumbersome bureaucracy. In addition to that, Ackers (2001) noted that the priority attached to individual factors may vary across the life span of an individual, thus making individuals at different stages of their career less likely or more likely to migrate from or to return to their home country. These factors related to satisfaction with research environment suggest some possible factors, which may determine the extent of readjustment of researchers upon return to Kazakhstani higher educational institutions. 
Several important observations can be made about the available literature. First, almost all the available theories are structuralist in nature. They view the process of re-integration as re-adjustment, where change happens only with the returning scholar, who modify their behavior and fit the fixed environment. The behavior of a returnee is determined by the structure and accessibility of domestic and international scholarly networks, research governing and funding institutions, academic organizations and cultural norms. While Acker (2005) suggests incorporating an agency perspective, she understands it more in terms of non-economic factors related to volition of the researcher. She argues that economic factors frequently fail to explain the immigration decision of highly skilled migrants and even under frugal economic conditions scientists are not inevitably pushed to immigrate. It is in this respect, according to Acker (2005), that they display agency.

While we agree with the limited nature of the structuralist perspective, we want to push the agency perspective suggested by Acker (2005) even further to argue that in the process of re-integration of returning scholars the change is not constrained to the researchers themselves. The returnees may also modify the environment in the process of adjustment. In fact, the various government and nongovernment scholarships provided for doctoral studies in Kazakhstan expect the alumni to be "change agents". This task is frequently clearly articulated in the official descriptions of the scholarship schemes and is inculcated in the scholarship recipients during orientations, alumni events, in addresses of officials and media statements. In this connection, we believe that the term "re-adjustment" is a misnomer since it assumes passive fitting to the existing context, and the term "re-integration" may be more appropriate. With this modified agency theory in mind, we expect to see not only adjustment, but also transformative strategies in the behavior of our participants.

The second observation from the literature is that it prompts several levels at which re-integration takes place. First, an individual should re-integrate at the organizational level, whereby they should become a part of the employing university or a research team. Second, an individual should reintegrate at the institutional level, whereby they should learn how to play the ropes of the local and international funding and research governing arrangements, as well as become an integral part of the global and domestic scholarly societies. Third, an individual should re-integrate at the societal/cultural level by reinterpreting cultural beliefs and norms in a new way informed by the experiences abroad. In addition, the multi-level process may have several possible outcomes, whereby an individual may (1) physically stay in a new location, but remain linked to the previous country, (2) become disconnected with the previous country, (3) become dually connected to both contexts, or (4) become marginalized and leave the profession. Another important observation from the literature is about the importance of both individual and relational aspects in re-integration. Reintegration is highly dependent on how one manages their networks at home and abroad. Finally, literature clearly indicates that the extent of re-integration is determined by the accuracy of an individual's expectations about the reality they will face upon return.

\section{Methods}

The overarching research question of the study was: how do Kazakhstanis who received a Ph.D. abroad transition as researchers upon their return to the home country? More specifically, we wanted 
to understand (1) what challenges and opportunities they face as scholars, (2) what factors affect this transition and (3) what strategies they use in the process of transition.

The central phenomenon in the study is the research-related experiences of Kazakhstani scholars, who returned from international mobility programs, as well as the field of influences on the research experiences, as perceived by the researchers themselves. Since we sought to develop an in-depth understanding of the central phenomenon and to identify the variables, which could be used to describe it, we chose a qualitative approach as more appropriate for the study (Creswell, 2013). More specifically, we used an in-depth descriptive qualitative interview design, where we relied on surface interpretation of the data to arrive at an in-depth description of a phenomenon, which most of the participants of the study or other researchers would agree on (Sandelowski, 2000). Semi-structured face-to-face and Skype interviews were chosen as the method of data collection, which allowed us to understand the experiences of the participants in words of the participants themselves and which equipped us with some flexibility to dynamically follow up on unexpected themes in the process of interviewing (Creswell, 2013).

The participants of the interviews were selected out of individuals, who were employed as faculty, researchers or research-active instructors in universities and non-academic research centers, who spent at least six months in Kazakhstan after their return and who were within five years of graduation. We used a maximal variation sampling approach, which allowed us to reveal variability in the experiences possible in the population, as well as to explore the differences, which may be related to the variation. The participants were varied on such characteristics as gender, area of specialization, country of doctoral training, type of funding received for doctoral studies, and experience in Kazakhstani academia prior to departure. The sampling frame was constructed using a combination of approaches. First, we obtained lists of alumni of various programs, such as "Bolashak" (Presidential scholarship for study abroad) and "Talap" (Nazarbayev University scholarship for study abroad for employees with Master's degrees), from the program administrators. Second, we identified some individuals and their contacts by searching alumni groups on social media, as well as by searching faculty/researcher profiles on the websites of some key national- and regional-level public and private universities, which tend to attract foreign Ph.D. holders. We also added to the frame the names of individuals, whose contacts were obtained by using a snowball approach.

Overall, 30 individuals were interviewed. We were able to achieve variability in terms of countries of study. We had participants from Europe - Germany, the UK, Norway, Hungary; North America Canada and the U.S.; Asia and Middle East - Turkey, Japan, China, Malaysia; as well as from postSoviet Eurasia - Russia. The sample was relatively balanced in terms of gender (45\% males and 55\% females). The participants represented a variety of fields, including engineering, natural, social, biomedical and applied sciences. The sample included individuals employed as junior research personnel (45\%), faculty (35\%), as well as instructors (20\%). The type of funding that the participants received for their studies included government scholarship (Ex.: Bolashak), international agency scholarships, foreign university scholarships, KZ university scholarships (Ex.: Talap), and self-funding. Sixty percent of the participants were from an international level research university, which offers most attractive salaries and employment conditions in the country. Other participants 
represented national level public research-intensive universities, as well as some research- and teaching- oriented private Western-style universities.

Interviews were conducted face-to-face or by Skype. The protocol included questions collecting information about demographic characteristics of the participants, as well as questions, which allowed to understand how the participants enrolled into doctoral programs, what their experiences during $\mathrm{PhD}$ studies were, how they transitioned to their employment in Kazakhstan, what aspects of the transition process affected their ability to engage in research, and what strategies they used in the process of transition in terms of their research activity.

\section{Results}

Experiences, factors, and strategies related to the nature of the doctoral program

One of the key observations of our analysis was that the nature of the doctoral program had a lot to do with the ease of transition to research environment in Kazakhstan. The country, where an individual pursued their degree, the major in which they specialized, the organization of the advisory group, as well as funding arrangements influenced the process of re-integration. These influences were found to determine the extent to which returnees experienced such challenges as: (1) lack of understanding of funding mechanisms and research administration practices at universities in Kazakhstan; (2) lack of experience dealing with bureaucracy and academic organizational culture; (3) lack of connections with the national scholarly community and lack of understanding of how some of the informal relations operate; (4) lack of awareness of strategically important research issues and problems, which have a higher likelihood of being funded by the government; (5) lack of understanding of unique challenges of conducting research in the local environment related to access to data and access to participants.

\section{Country of study}

The transition experiences of scholars were related to the country where they pursued their doctoral degrees. The participants, who pursued their doctoral education in Russia and in Turkey reported less issues from the list of challenges presented above. They had better awareness of relevant research topics, the organization of research-funding and research-administration mechanisms in Kazakhstan, administrative and data-collection challenges in conducting research in the country, as well as had better connections with the local and regional scholarly communities. This better awareness was a result of being advised by a supervisor with some understanding of research conducted in Kazakhstan, and of being involved in collaborative research projects involving Kazakhstani researchers.

Many of the ties with Russian research groups and institutions, which were established in the Soviet times, when Russia and Kazakhstan were two integral parts of a national research system, continue to exist nowadays. Research groups from the two countries often collaborate on various projects sharing interest and methodological approaches. Some of our participants were junior members of Kazakhstani research teams, who were intentionally sent for doctoral training to 
Russian research groups, where they became employed as a research assistant on collaborative projects.

Turkey has developed strong relationships with Kazakhstan after the dissolution of the Soviet Union. Turkish government has invested into establishment of several Turkish-Kazakh universities, which employ Turkish faculty, send their alumni to study to Turkey, and maintain close research connections with Turkish research community. One of the participants with specialization in international relations told us about a highly effective faculty development program at her university, which is based on doctoral training of most talented alumni at a Turkish partner. She emphasized that instructors in the doctoral program conducted research on Central Asia and Kazakhstan, were very knowledgeable about issues of national importance, relevant literature and local methodological challenges. They often supervised groups of Kazakhstani students and encouraged them to produce collaborative publications, as well as involved them in collaborative research projects with Kazakhstani faculty:

During the period of 2010-2014, when I was pursuing my Ph.D. degree at X university, there were over 30 other doctoral students from my Kazakhstani university... There were four of us majoring in international relations, who were advised by the same Turkish professor... We all wrote dissertations on Central Asia. The adviser helped us to choose topics, which were highly relevant for the region and encouraged us to collaborate on publications....

\section{Area of specialization}

Another factor affecting the process of integration was related to the area of specialization as a doctoral student. Returnees majoring in medicine, natural sciences, and engineering were frequently involved in projects conducted by their advisers during their studies. As a result, they had better practical experience in conducting research, in managing research teams, in writing grant proposals and articles, and in operating cross-border and interdisciplinary collaborations than scholars specializing in social sciences and humanities, where such opportunities were limited, and practical experience was constrained to individually written dissertation.

One of our participants, who majored in medicine, told us about her involvement in a project during her studies in Japan:

There was a huge project, Hiroshima-Semey project, of which I was a part. Within this project, a group of Japanese doctors came to Semey, Kazakhstan, to provide free dental treatment and diagnostics for people in the area affected by radiation. At the same time, our team collected some samples for a DNA study of radiation-induced malformations...

In addition to that, social sciences in Kazakhstan have a much lower status than natural sciences and engineering due to the legacy of ideological control in the Soviet Union. In contrast, due to the government's commitment to promoting innovation, researchers in sciences receive greater support in the form of grants, access to world-class research labs and facilities, and involvement in administrative and policy decisions. 
One of our participants specializing in engineering told us how he got involved in a funded research project a year before graduation and how quickly he progressed in leadership positions at a local university because he had a Western Ph.D. degree in a field in high demand:

Prior to the end of my studies I was already a part of a research team funded by the Ministry of Education... They asked me to join the team as a junior researcher first, but as soon as I got my Ph.D., they made me the principal investigator on the project...I was also appointed as a Chair of the department as soon as I arrived. Then, within a year, I became a Vice-Dean and a month later was promoted to be a Dean of the Department of Space Technology.

Organization of the advisory group

One of the most notable characteristics of a doctoral program, which seem to have an influence on the process of transition of returning scholars is the organization of the advisory group. Over a third of our participants had a more senior Kazakhstani researcher involved in a formal of informal advisory capacity in the process of their study. In most of the reported cases, the Kazakhstani adviser was a former undergraduate or a Master's supervisor, who was well established as a researcher. The supervisor was often well connected abroad, had on-going collaborative research projects with foreign universities and assisted the student with placement at a partner university.

The assistance of the Kazakhstani advisers ranged from basic suggestions on a proposal topic, which was relevant for Kazakhstan, to collaborating on grant applications and publication, as well as more comprehensive involvement of the student in existing research projects as an apprentice. Most beneficial for students was an arrangement whereby a Kazakhstani researcher closely collaborated or shared similar interest with the supervisor in the doctoral program. In such cases, the students developed more accurate expectations about research context in Kazakhstan, learned how to conduct research in both countries and managed to integrate well in the global and local scholarly societies even before their graduation.

One of our participants, a physicist, who completed a Ph.D. in Italy, shared the following description of the role of his Kazakhstani adviser and the advisory arrangement:

My supervisor was a part of a research school from the Soviet Union. He is a famous physicist and an expert in quantum physics. When he came back from Russia, he created his own school and I was a part of it....My Italian supervisor was quite famous in astrophysics...My Kazakhstani adviser used to go to international conferences organized by the Italian adviser and they knew each other very well...During my study in Kazakhstan under supervision of the Kazakhstani scholar I had a chance to visit Italy and to present at seminars, after which the Italian scholar invited me to pursue a Ph.D...The Kazakhstani adviser was my informal committee member and he was involved in everything I did... Because of difference in research interests between my advisers, I ended up being involved in several research projects - some with the local, some with the foreign supervisor... Within three years I managed to publish 8 papers...At the end of my studies I returned to my previous lab to work with my supervisor and I still continue collaboration with the Italian one. 


\section{Funding arrangement}

One of the most of important factors, which influenced the process of re-integration of returning scholars was the type of funding that they had for their Ph.D. studies. One interesting pattern that we noticed is that students, who received the highly prestigious government-sponsored "Bolashak" scholarship, as well as students, who received funding from their employing universities generally re-integrated more smoothly than those, who were funded in other ways. Due to the highly competitive nature of the "Bolashak" scholarship, the above the average level of ambition typical of the recipients, and the government promoted image of "Bolashak" alumni as having international level expertise and leadership potential, "Bolashak" scholars are normally welcome in organizations, receive more support than graduates of local universities, and have better opportunities for promotion. Many of them easily find employment in research-intensive and Western-style universities, where the environment is more conducive to research. Those scholars, who worked at Kazakhstani universities prior to their studies and who received scholarships from their institutions often have the contractual obligation to come back to their previous place of employment and a promise of an increase in salary and promotion. While the increase in salary and the position that they receive may not fully meet their expectations, these scholars have more accurate expectations about the research environment, feel less frustrated and integrate faster. Meanwhile, the non-Bolashak and the unaffiliated returnees often experience issues with finding a research position and are marginalized to instructional roles.

\section{Experiences, factors, and strategies related to research environment}

Some of the factors, which determined the process of adjustment of returning scholars were related to the overall research environment in the country. The participants talked about many of the environmental influences, such as lack of industry demand for research, poor enforcement of intellectual property rights, low web presence of research institutes, centers, and groups, which do not allow potential research collaborations to develop, low research capacity of universities, and a low number of researchers, who have sufficient training to be able to produce global-level research. However, most salient of the themes in the interviews were related to lack of research funding and debilitating bureaucracy, which stifles research.

\section{Funding mechanisms}

Access to funding was one of the most important factors affecting adjustment. While researchers in the international research university (Nazarbayev University) complained mostly about ineffectiveness of and lack of transparency and subjectivity in distribution of funding, scholars in other universities were also concerned about the level of funding. Funding was essential for all researchers for conference attendance. Few universities in Kazakhstan sufficiently subsidize conference travel and in the absence of grants researchers often get cut from the global research community unable to make new and to reinforce old connections and to get exposed to new research directions and ideas via conference participation. In addition to that, lack of funding does not allow experimentalists to equip their laboratories. Many of the scholars in experimental physics, chemistry, biology and other laboratory disciplines have trouble publishing in the first years until they manage to equip their labs and to hire lab assistants to run the experiments. 
This is the story of one applied physicist, who graduated from the U.S. The story clearly demonstrates some of the themes discussed above:

During my first three years there were a lot of challenges. One of the most important ones was lack of financial support for research...At the level of government funding it is very difficult to win projects. Usually projects are won by people who have some power at the university or at ministerial level...This year I did not get any support. My grant application was denied although it had high scores from external reviewers. For me it was a disappointing thing because all projects with lower scores received financial support. They won not because they were important for our economy or for our country, but because the principal investigators had some relationship with the Ministry of Education...

\section{Legal/regulatory context and bureaucratic control}

A factor, which was even more frustrating for our informants than the lack of funding, was the tight bureaucratic control in academic organizations, which many of them found highly inefficient after experience of conducting research abroad. Not only grants were described as difficult to obtain, but they were also criticized for being hard to use once a grant was received. Every step of the research process starting from obtaining a letter of support to approach research sites to hiring research assistants, subcontracting data collection, having a conference trip approved, a software purchased, or equipment or chemicals delivered on time took a huge amount of time and required significant effort from the principal investigators. Researchers ended up spending most of their time filing paperwork and reports, as well as collecting signatures instead of running experiments and writing papers. As a result, some scholars abandoned any attempts to apply for local funding changing their work in more theoretical and desk-based directions. Others tried to collaborate with international partners on grant applications, choosing to play a secondary role, so that the money is processed on the partner's side. One returnee, who graduated from Britain with a degree in Finance described the bureaucratic environment in the following way:

The people, who do finance and accounting...I feel they lack experience... They have not seen how these things can work better... They just keep fulfilling this sort of mindless list of technical things that they need to accomplish without understanding ... the end goal... how this process can be conducted so that it minimizes costs and maximizes output...And this has created a lot of stress...It's impeding our research... They don't seem to trust us, researchers...that we can spend money wisely... and that we know how to do research... When we wanted to buy a specific model of a computer, they told us...you don't need his model... you can buy something cheaper...As if they know how to do research better than researchers... It looks like this budget was given not for the sake of research, but for the sake of administering the budget...

The high level of bureaucracy and unpredictability of funding streams makes some researchers move into new research directions in which they were not trained or tame their ambition. Some experimentalists move away from laboratory work to modeling and theoretical directions.

This is how one UK university alumnus specializing in robotics described changes in his research agenda: 
Initially, there was more targeted program funding available. I got a Ministry (of Education and Science) grant. But then in 2015, after an economic decline, the funds decreased... We had very high hopes that we will build robots at the beginning. But now we became more realistic. We focus on more algorithmic work. We cannot focus on huge things like building robots because getting small electronic components is a headache here. It takes too long to receive them, you cannot compete with any other countries, especially China. Right now, I am focusing on robot controls, programming.

Experiences, factors, and strategies related to organizational context

Organizational factors were also evident in our interviews. While challenges were experienced by returnees at various types of organizations, there were some differences depending on the characteristics of organizations, which will be discuss below. In addition, while looking for participants, we noticed that most of the doctoral program graduates settled down in top public and private national level and international research universities, which means that other types of institutions could not offer even bare minimum in terms of research to attract the highly qualified faculty. Two factors were most notable at the organizational level.

\section{Institutional type}

One of the most evident differences we noted was between public national-level and private research universities. Most participants from public universities, with some exceptions, reported greater challenges with a high level of corruption and bureaucratic control, paternalism and resistance from the old Soviet-trained army of researchers. The old researchers often lacked the knowledge of English and possessed an outdated expertise and lower motivation to conduct high quality research. A participant, who graduated from the UK with a degree in robotics described his frustration at working with the old Soviet-trained colleagues:

They asked me to work with them on their grants. There were so many delays and shadow schemes during the work on the project. I do not want to deal with the kinds of people and projects any more.

Another participant with a major in public policy described her struggles at a public university in the following way:

We have to teach four courses per semester, which includes proctoring exams, grading, and advising... Then we have all sorts of irrelevant administrative responsibilities: we have to visit dorms, mentor students in student organization and activities, attend multiple meetings - all of these barely leave any time to conduct research... Then we have poor resource base - limited library holdings and database access, outdated research software, lack of conference funding... We have to pay for conference trips out of our own pocket.

On the contrary, scholars at a private international level research university recognized that the university pays more competitive salaries, offers more resources than other universities to conduct international level research, attracts more talented student employees, which increases the chances for potential collaboration and for hiring more effective research assistants, as well as has less bureaucracy, and greater research support from leadership. 


\section{Human resource structures}

Absence of full-time long-term contracts for research positions at universities was one of most essential organizational factors affecting returning scholars. In Kazakhstan, most universities are teaching-oriented. While the expectation from many research universities is nowadays to produce more publications financial incentives for pursuing research are low compared with cost of conducting research given the limited funding, outdated facilities and library holdings, as well as low English language ability and research skills of faculty. The salary of a faculty is based mostly on teaching hours, which makes the position of a faculty unattractive for researchoriented doctoral recipients from abroad. Meanwhile, full-time research positions are funded mostly from grants, which, as has been described above, are hard to receive and do not offer consistency in access to money. The situation has two serious impacts on returnees. First, there is a high loss of recent returnees, who struggle for some time and then leave research for better paid and more predictable positions in other sectors. Second, more senior scholars can have trouble building stable research teams due to difficulty in attracting and retaining talented junior researchers.

\section{Experiences, factors, and strategies related to professional associations and networks}

One of the main issues, which faced returnees in Kazakhstan was difficulty in growing their professional networks at home and abroad, and the accompanying isolation from the extraorganizational community of scholars specializing in the same field. For many returnees maintaining ties with colleagues from abroad was limited to interaction with individuals, whom they knew from their doctoral studies - their advisers, other faculty, peers, former collaborators, and members of research teams. Attendance of conferences was largely unaffordable and lots of participants complained that their institutions did not provide sufficient funding for participation in meetings of scholarly societies. One of the reasons for difficulty in attracting international collaborators, which was mentioned by several participants, was significant time difference and peripheral status of relatively underfunded Kazakhstani universities, which are not particularly attractive for research partners from abroad.

In addition, many returnees did not integrate well with the local scholarly societies and networks. Several reasons were indicated as an explanation for the lack of integration. First, participants referred to the nascent state of development of local professional societies and conferences. Only in some disciplines, examples being physics and mathematics, there are small, but relatively strong scholarly societies in Kazakhstan. Most of the conferences are organized by universities rather than by professional societies, lots of them are multidisciplinary in nature and are planned around low quality presentations. Few of the conferences are attractive for internationally trained researchers, including those, who are originally from Kazakhstan. Second, the professional communities in Kazakhstan often act like informal networks, which are motivated by the desire to exert influence on funding agencies, institutional leadership and resources, and policy makers, and which tend to have exclusive membership and are hard to penetrate for a novice researcher without connections in the networks. The networks are dominated by the older generation of researchers (referred to as "old dinosaurs" by one of our participants), who were trained in the Soviet Union and who achieved prominence in research and influence in power circles many 
years ago. These "dinosaurs" feel threatened by the younger generation of researchers and may limit access to money, influence, and local scholarly circles. Due to the notorious reputation of these circles as being incompetent and corrupt, young researchers try to avoid any affiliation or collaboration with the "old dinosaurs".

One of our participants, with a degree from the U.S. and specialization in Robotics said:

I do not want to collaborate with local research teams in public universities I once joined a project in 2015. I was invited by an established professor from Eurasian National University and they asked me to work on one of their grants. I was a co-PI. There were so many delays and "shadow schemes" during the work on the project, that I do not want to deal with such networks and projects any more.

A third reason, which was indicated by our participants as contributing to the lack of integration in the local scholarly community was poor presence of local researchers and research centers on the Internet. Several returnees indicated that they were very interested in collaborating with other talented local scholars, however they could not locate accurate information on the web about organizations and researchers specializing in their field, about their on-going research projects, as well as contacts.

The lack of opportunities to connect with researchers at home and abroad, who specialize in the same field, motivated many of our participants to connect with other Kazakhstanis, who received doctoral education abroad and who worked as researchers. During our interviews, we learned about the existence of at least two organized groups of young researchers trained abroad, which were established for the purpose of connecting the very small and highly isolated community of researchers capable of producing world-level research.

The young researchers formed their own association pursing three primary purposes: (1) to assist each other in cultural transition; (2) to improve information exchange and networking; (3) to collectively negotiate their pay and employment conditions with university administration and with national-level policy makers; (4) to counteract the old informal networks. These associations serve, to some extent, as proto-professional societies, which may split into scholarly societies later, as the number of new researchers increases.

A graduate of a Japanese university with a degree in Chemistry described the rationale for the creation of one of the associations:

We created this association so that we could be in touch with researchers around Kazakhstan. We have an information vacuum. Websites are not updated, phones can never be reached. There are 266 research organizations in Kazakhstan, but we know so little about them. If we set some kind of platform of young researchers from these organizations, we can quickly get information about the projects they are working on and the facilities they have. This will allow us to collaborate locally...In addition, we are invited to different types of events by the Ministry of Education and Science... For example, we were consulted during the process of development of the National Research Development Strategy. 
Interestingly, the members of the association indicated that similar associations of young researchers exist in other post-Soviet countries, including Russia and Belarus, and that their group have taken measures to connect with these associations. This implies that informal networking may be used by younger generation of researchers as a solution of the problem of closed existing networks throughout the post-Soviet space.

Experiences, factors, and strategies related to larger cultural context

The transition of returnees was also complicated because of the larger cultural context, which affected their personal and professional lives. A graduate of a Japanese university, for example, described her challenges in leading research teams in the early years of working as a junior researcher, when she could not ensure that her subordinates meet deadlines. She compared the high level of discipline and responsibility that she observed in Japanese workers with the poor work ethics of Kazakhstani employees.

A graduate of a US university with a major in Chemistry described how personal-level problems affected his ability to be productive in research. He described the conflicts he had with his spouse, who did not want to return to Kazakhstan and had trouble getting used to the new life after five years of living away from relatives and raising children in another country. The children were English-speaking. They struggled at school and had issues in communication with extended family members. The wife was considering a divorce and nobody in the extended family could completely understand the reasons for the conflict. He mentioned feeling very lost and lonely at the time, as well as needing some sort of psychological support.

Finally, he described a clash between the very high expectations of the returnees in terms of their salary, status, and living conditions and the hostility of some members of the general public towards individuals educated abroad, who, in their view, overestimated their abilities, spent too many public resources for their education and had completely unjustifiable demands to their employers:

For anyone coming back from a more developed to a less developed country, there is a cultural shock and frustration. Most of the Ph.D. holders need some reassurance, especially, when they come back voluntarily rather than because of some contractual obligations. They are highly motivated to advance science in their own land, but they need incentives. Just think about it, they studied abroad in countries like the US for three to five years, they know how well people can live, especially if they have expertise similar to theirs. They come back and expect a good treatment. And if this is not happening, they start thinking about going back. Imagine somebody, who has just graduated from overseas: We trained him five years here in KazGU on a grant, then we trained him on "Bolashak" in the UK, and then, somehow, he went to the US, and he is now 35 years old. He spent almost 19 years of his life in intensive and challenging training. He is now back, very fresh and eager to do things. But he also wants to be appreciated for what he achieved. Meanwhile, what he hears is comments from an arrogant administrator, who says: "You have used up pubic money and now want more things! You are never going to get them!"

\section{Discussion}


The results of our study are very consistent with prior research in various disciplines exploring the process of re-integration of internationally mobile individuals. As has been suggested by prior research, for example Black's (1991) Model of International Adjustment, the process of reintegration is multidimensional and involves the process of socialization at the individual, organizational, institutional, as well as cultural levels. The factors shaping the process of socialization take place at each of these dimensions. At the individual level, the type of doctoral training received, including the major, the country of study, the type of funding arrangement, as well as the structure of the advisory groups determines the kinds of experiences that a student receives abroad, the opportunities that they may face upon return, as well as the extent of familiarity with the research environment at home and abroad, which shapes expectations and the process of adjustment. At the organizational level, research-orientation, the type of institutional control (private or public), as well as HR structures at the employing university determine the level of support an individual receives from the employing organization, as well as their confidence in their future employment and salary. At the institutional level, the ability to integrate with local and external professional networks is highly important. While contact with international community is essential for tracking new theoretical and methodological developments and for identifying collaborators with complementary knowledge, skills and access to resources; access to local professional networks gives influence in the processes of money and power distribution, as well as gives voice in policy decisions pertaining to research. Finally, at the cultural level, the process of reintegration may be hampered by psychological issues associated with reversed cultural shock and experienced not only by the returnee, but also by their family members.

In addition, prior research (Black et al., 1991; Kraimer et al., 2012; Lazarova and Caligiuri, 2002; Suutari and Brewster, 2003) argued that the extent of adjustment is largely determined by the accuracy of the returnee's expectations about the research environment. This was confirmed in our study. For example, as has been explained above, we noticed that scholars, who had prior experience in Kazakhstani organizations, who were supervised by a Kazakhstani scholar, or who were involved in research projects in Kazakhstan or with a Kazakhstani researcher during their studies tended to adjust better than those, who did not have the types of background. In addition, in accordance with organizational socialization theory (Bauer \& Erdogan, 2012; Chao et al., 1994; Morrison, 2002; Wanberg, 2012), this early exposure to the local research contexts allow them to learn the roles and routines of the work earlier, as well as to become integrated into the social fabric of an organization faster.

Finally, the previous literature (Berry, 1994; Ward, 2001) indicates several possible outcomes of adjustment, which we observed among our participants. Some of the scholars were able to integrate well and became fully-operational researchers. Some of these became more integrated in the international scholarly community building and expanding their connections in the international networks. They maintained the identity of a scholar that they developed during their doctoral studies. Others became more integrated in the local and regional scholarly networks, having socialized more to the local community norms. A few managed to integrate both internally and externally and to develop a dual identity functioning well both as a local and as an international scholar. Finally, some 
of the returnees did not adjust and left the scholarly career becoming more committed to teaching or leaving academia completely.

The most important finding of our study, however, supports our original idea that the process of integration of returning scholars is not limited to adjustment to the existing structures, as conceptualized in most of the prior research framed by structuralist perspective. It may also involve transformation of the environment by the young researchers as a manifestation of agency. As predicted by Acker's (2005) research on highly skilled migrants, economic structural constraints cannot unilaterally explain the exodus of highly qualified researchers from the profession and from the country. Researchers in Kazakhstan are frustrated not so much at the level of salary or benefits that they receive as at the conditions that are provided for active engagement in research, including fairness in distribution of funding, rigidity of bureaucratic control, corruption and impermeability of local informal scholarly networks, as well as poor recognition of the abilities and limited autonomy of internationally-trained scholars. This frustration, however, takes the scholars further than what is predicted by Acker (2005): Kazakhstani Ph.D. holders try to transform their environment by creating alternative informal networks of international alumni, which are used to lobby the members' interests with employers, to voice their concerns to policy makers, to fill information vacuum and to mobilized peers in order to counteract the omnipresent control by informal networks of older scholars. In doing so, the returnees are acting as change agents in accordance with the expectation of the many government-funded international mobility programs.

In summary, out study suggests three important recommendations for future research and policy. First, agency perspective seems to be a productive framework, which should be more carefully taken into consideration in the analysis of reintegration experiences of internationally mobile individuals. For policy makers the implication is that study abroad scholarships may indeed be effective in producing change agents in the process of reforms. Second, in countries with a small size of domestic scholarly community, professional networks specializing in different areas of research may not be present, but they may be substituted with informal or semi-formal protoprofessional societies, which are used by the participants for information exchange and power mobilization. Policy makers should encourage the creation of such networks and should support them once they are established. Finally, a closer attention should be paid in future research to the nature of the doctoral program, especially advisory team composition, and its impact on expectations management. Meanwhile, policy makers should consider introducing a mechanism for involvement of a research-active home-country supervisor on doctoral advising committees as a part of scholarship requirements.

\section{Funding}

This work was supported by the Nazarbayev University Faculty Development Grant Program [grant number 090118FD5306]. 


\section{References}

Ackers, L., 2005. Moving people and knowledge: Scientific mobility in the European Union. International migration, 43(5), pp.99-131.

Ackers, L., 2001. Legal employment and social aspects of researcher mobility. An Invited presentation to Education Research Association conference.

Adler, N.J. ,1981. Re-entry: Managing cross-cultural transitions. Group Organizational Management, 6(3), pp.341-56.

Bauer, T. N., \& Erdogan, B., 2012. Organizational socialization: The effective onboarding of new employees. The Oxford handbook of organizational socialization, pp.97-112.

Baumeister, R. F., \& Leary, M. R., 1995. The need to belong: desire for interpersonal attachments as a fundamental human motivation. In Sauskiene, R. (Ed.), Interpersonal Development, London: Routledge, pp.57-89.

Berry, J., 1994. Acculturation and psychological adaptation: an overview. In Bouvy, A-M., Van de Vijver, F., Boski, P., and Schmitz, P. (Eds.), Journeys into cross-cultural psychology, Amsterdam: S\&Z, pp.129-141.

Bhandari, R., 2017. Post-secondary scholarships for students from developing countries: Establishing a global baseline. European Journal of Education, 52(4), pp. 533-545.

Biddle, B., 1979. Role theory: expectations, identities, and behaviors. New York: Academic Press.

Black, J. S., Mendenhall, M., \& Oddou, G., 1991. Toward a comprehensive model of international adjustment: An integration of multiple theoretical perspectives. Academy of management review, 16(2), pp. 291-317.

Carraher, S.M., Sullivan, S.E., Crocitto, M.M., 2008. Mentoring across global boundaries: an empirical examination of home-and host-country mentors on expatriate career outcomes. Journal of International Business Studies, 39(8), pp. 1310-1326.

Chao, G. T., O'Leary-Kelly, A. M., Wolf, S., Klein, H. J., \& Gardner, P. D., 1994. Organizational socialization: Its content and consequences. Journal of Applied psychology, 79(5), pp.730-743.

Choudaha, R., 2017. Three waves of international student mobility (1999-2020). Studies in Higher Education, 42(5), pp. 825-832.

Cox, J. B., 2004. The role of communication, technology, and cultural identity in repatriation adjustment. International Journal of Intercultural Relations, 28(3), pp. 201-219.

Creswell, J. W., 2013. Research design: Qualitative, quantitative, and mixed methods approaches. Thousand Oaks, CA: Sage. 
Pearson, R. and Morrell, J., 2002. Knowledge migrants. The motivations and experiences of professionals in the UK and Work Permits. Department of Trade and Industry (DTI).

Gribble, C., 2008. Policy options for managing international student migration: the sending country's perspective. Journal of Higher Education Policy and Management, 30(1), pp. 25-39.

Gullahorn, J. T., \& Gullahorn, J. E., 1963. An extension of the U-curve hypothesis. Journal of Social Issues, 19(3), pp. 33-47.

Hall, E. T., 1959. The silent language. New York: Doubleday.

Hellemans, A., 2001. Beating the European brain drain. Naturejobs special report. November 22, 45 .

Kapur, D., \& McHale, J., 2005. Give us your best and brightest. Washington, DC: Center for Global Development.

Kehm, B. M., \& Teichler, U., 2007. Research on internationalisation in higher education. Journal of Studies in International Education, 11(3-4), pp. 260-273.

Knight, J. \& De Wit, H., 1995. Strategies for Internationalization of Higher Education: historical and conceptual perspectives, in H. De Wit (Ed.) Strategies for Internationalization of Higher Education: a comparative study of Australia, Canada, Europe and the United States of America, Amsterdam: European Association for International Education, pp. 5-33.

Kraimer, M.L., Shaffer, M.S., Harrison, D.A., Ren, H., 2012. No place like home? An identity strain perspective on repatriate turnover. Academic Management Journal, 55(2), pp. 399-420.

Lazarova, M., Caligiuri, P., 2002. Retaining repatriates: the role of organizational support practices. Journal of World Business, 36(4), pp. 389-401.

Martin-Rovert, D., 2003. Opportunities for outstanding young scientists in Europe to create an independent research team. European Science Foundation (online). Available at http://www.esf.org/publication/167/OpportunitiesFinal.pdf.

Morrison, E. W., 2002. Newcomers' relationships: The role of social network ties during socialization. Academy of Management Journal, 45(6), pp.1149-1160.

Nicolescu, L., \& Galalae, C., 2013. A systematic literature review on students' international mobility and cultural adjustment. Management \& Marketing, 8(2), 261-282.

Perna, L. W., Orosz, K., Gopaul, B., Jumakulov, Z., Ashirbekov, A., \& Kishkentayeva, M. 2014. Promoting human capital development: A typology of international scholarship programs in higher education. Educational Researcher, 43(2), pp. 63-73. 
Perna, L. W., Orosz, K., \& Jumakulov, Z., 2015. Understanding the human capital benefits of a government-funded international scholarship program: An exploration of Kazakhstan's Bolashak program. International Journal of Educational Development, 40 (2015), pp. 85-97.

Sagintayeva, A., \& Kurakbayev, K., 2013. Internationalisation of Higher Education in Central Asia: The Case of Kazakhstan. In Stiasny, M. and Gore, T. (Eds.), Going Global: Identifying Trends and Drivers of International Education, Bingley, UK: Emerald Group Publishing, pp. 17-27.

Sandelowski, M., 2000. Focus on research methods-whatever happened to qualitative description?. Research in Nursing and Health, 23(4), pp. 334-340.

State Program for the Development of Education and Science in the Republic of Kazakhstan 20162019, No.205, http://psu.kz/images/october2014/gpro.pdf.

State Program for Industrial and Innovative Development of Kazakhstan 2015-2019 (SPIID), August 1, 2014, https://primeminister.kz/en/page/view/gpiir

Suutari, V., Brewster, C., 2003. Repatriation: Empirical evidence from a longitudinal study of careers and expectations among Finnish expatriates. International Journal of Human Resource Management, 14(7), pp.1132-1151.

UNESCO Institute of Statistics (2018). International student mobility in tertiary education data. Retrieved from http://data.uis.unesco.org/Index.aspx?queryid=172

Wanberg, C., 2012. The Oxford handbook of organizational socialization. Oxford, UK: Oxford University Press.

Ward, C., 2001. The A, B, Cs of acculturation. In Matsumoto, D. (Ed.), The Handbook of Culture and Psychology. Oxford, UK: Oxford University Press, pp. 411-445.

World Bank. (2010). Innovation Policy: a guide for developing countries. World Bank Group.

Yudkevich, M., Altbach, P. G., \& Rumbley, L. E. (Eds.)., 2016. International Faculty in Higher Education: Comparative Perspectives on Recruitment, Integration, and Impact. Oxford, UK: Taylor \& Francis. 